\title{
Sleep Manipulation Prior to Airborne Exercises
}

\author{
Capt M C M Bricknell \\ BM, RAMC \\ Regimental Medical Officer \\ 1 PARA, Aldershot, Hants
}

SUMMARY: Airborne operations may demand an intense level of activity prior to parachuting. In addition the movement of troops to the theatre of operations may well involve the crossing of several time zones. These factors may well deprive the troops of sleep. Furthermore, a parachute assault may well be at night leading to a long period without rest. Scheduled sleep may help ameliorate this sleep deprivation. Studies have shown that daytime sleep prior to overnight activity can improve performance.

A study was undertaken to see whether temazepam would improve daytime sleep during a scheduled rest period compared to placebo.

The results showed a significant increase in the average sleep period in the group taking $20 \mathrm{mg}$ and $10 \mathrm{mg}$ of temazepan compared to placebo. The quality of sleep was also improved yet there was no difference in subjective alertness between the groups six hours post ingestion.

\section{Introduction}

One of the main features of parachute exercises and operations is limited time to organise troops and equipment. Furthermore the mounting of an operation may involve a strategic move from the UK to a forward mounting base before insertion into theatre. The total distance from the UK to the operational area may well involve the crossing of several time zones.

The risk from anti-aircraft weapons may force the parachute insertion to be carried out by night. The initial phases of the operation will be a period of intense activity with little opportunity for rest.

All of these factors will combine to deprive the troops of sleep both prior to and during the operation. In order to ameliorate the situation it is sometimes possible to program a period of rest prior to the parachute operation.

Various studies have shown that short anticipatory sleeps prior to a period of sleep deprivation will improve performance $(1,2)$. Hypnotics have been shown to hasten the onset and improve the quality of sleep when administered at night(3). However their value in normal subjects in the absence of a sleep debt is less certain. The benzodiazepine, temazepam, in the capsule formulation has some useful characteristics. It is rapidly absorbed and will aid sleep onset relative to placebo $(4,5)$. It is rapidly metabolised with no long-acting metabolites and no persistent effects on wakefulness. It has a half life of 9-12 hours in normal healthy volunteers (6-10). It would therefore seem an appropriate drug to use to aid sleep during a period of scheduled rest.

A study was undertaken to test the value of temazepam as an aid to sleep during a period of daytime scheduled rest prior to a parachute exercise.

\section{Method}

Exercise Red Lanyard was a 1 PARA parachute exercise undertaken between 21 and 28 March 1990. This involved preparation for parachuting during 21-24

March and parachuting on 24 or 25 March dependent on the weather. It was planned to undertake this trial during the daytime scheduled rest period prior to parachuting.

Each company was randomly allocated to receive 0 placebo (multivitamin capsules), $10 \mathrm{mg}$ of temazepam, or $20 \mathrm{mg}$ of temazepam (in capsule formulation) such that there were two companies taking each tablet. Each soldier was offered the choice of taking the drug or not Neither the soldiers taking the tablet nor the medicalo officer administering the trial knew which tablet eacho company was allocated. Each soldier was to complete at questionnaire after their sleep to assess the effectiveness of the tablet offered.

The questionnaire recorded whether a tablet was taken and the length of sleep achieved. There were two linear analogue scales to record alertness after waking and the quality of sleep, each measuring on a scale from 0 to 10 . Finally each soldier was asked whether he thought the tablet helped his sleep.

After a normal night's sleep, the battalion had a period of scheduled rest from $1330 \mathrm{hr}$ to $1930 \mathrm{hr}$. The parachute descent was planned for $0500 \mathrm{hr}$ the following morning but was delayed because of adverse weather.

\section{Results}

There was a total of 312 soldiers in the battalion parachuting, of whom 288 completed a questionnaire (a response rate of $92.3 \%$ ). Table 1 shows the numbers in each group who took the tablets.

Support Company, Command Company and Administration Company are not directly comparable as the distribution of age and rank within each reflects their special requirements. In addition Support Company had a significantly higher proportion not taking the tablets $(39 \%)$ compared to the other companies (range 17$5 \%$ ). Therefore the analysis compares $\mathrm{A}, \mathrm{B}$ and $\mathrm{C}$ Companies and the group that opted to not take a tablet. 
Table 1

Numbers participating in the study by company

\begin{tabular}{lcccc}
\hline Company & $\begin{array}{c}\text { Tablet } \\
\text { offered }\end{array}$ & $\begin{array}{c}\text { Not taking } \\
\text { tablet }\end{array}$ & $\begin{array}{c}\text { Taking } \\
\text { tablet }\end{array}$ & Total \\
\hline A & 20mg Tem & 12 & 58 & 70 \\
Command & 20mg Tem & 6 & 52 & 58 \\
Admin & 10mg Tem & 4 & 43 & 47 \\
C & 10mg Tem & 3 & 46 & 49 \\
B & Placebo & 2 & 39 & 41 \\
Support & Placebo & 9 & 14 & 23 \\
Total & & 36 & 252 & 288 \\
\hline
\end{tabular}

A Company took $20 \mathrm{mg}$ temazepam, C Company took $10 \mathrm{mg}$ temazepam and B Company took the multivitamin preparation.

Non parametric methods were used throughout in the statistical analysis. In the analysis of sleep length, differences between groups were tested by the KruskalWallis one-way analysis of variance, or, when only two groups were being compared, by the Mann-Whitney $U$ test. The Kolmogorov-Smirnov two-sample test was used to test for group differences in subjective alertness and quality of sleep, while the analysis of the question 'did the tablet help?' was based on two way frequency tables, with the goodness of fit tested by the Pearson chisquared statistic. Whenever simultaneous comparisons were made between pairs of groups, the size of the test was adjusted by the Bonferroni inequality.

The cumulative frequency graph (Fig 1) shows the sleep length reported within each group. Longer sleep was reported in A (20mg temazepam) than in C $(10 \mathrm{mg}$ temazepam, $p<0.01$ ) and for both $A$ and $C$ compared to $B$ (placebo, $p<0.001$ for both). The mean sleep length for A was 247 minutes, C 203 minutes and B 120 minutes. For those not taking a tablet by choice there was no difference in sleep length compared to $A$ and $C$ companies but a marked difference compared with $\mathrm{B}$ $(\mathrm{p}<0.001)$.

The quality of sleep (Fig 2) was better for both $A$ and $C$ Companies than in $B(p<0.001$ for both) but there was no significant difference between $A$ and $C$. The group that took no tablet reported a significantly better quality of sleep than B Company but no difference compared to $A$ and $C$.

There was no significant difference in subjective alertness (Fig 3) between the four groups. Figure 4 shows the numbers claiming that the tablet helped their sleep for all companies. The percent reporting a benefit in $\mathrm{A}$ and Command Companies ( $20 \mathrm{mg}$ temazepam) was markedly greater than those in B and Support Companies (placebo).

\section{Conclusions}

This double blind placebo controlled trial produces the obvious conclusion that sleeping tablets will put soldiers to sleep. However there is more that can be deduced. Firstly, if offered sleeping tablets the majority of troops will take them $(60-95 \%)$. A tablet of $20 \mathrm{mg}$ temazepam will ensure $90 \%$ of troops can sleep for at least three hours and $100 \%$ of soldiers will be awake at six hours. This compares with placebo giving an average of two hours sleep. For troops choosing not to take a tablet their sleep seems to be as good as those taking $20 \mathrm{mg}$ of temazepam. Therefore there would be no benefit in forcing soldiers to take a tablet as those who choose not to take it seem to have no problem sleeping.

Temazepam produced a significant improvement in the perceived quality of sleep compared with placebo. Yet there was no residual effect on alertness. There was a clear opinion that taking $20 \mathrm{mg}$ temazepam helped sleep.

This study shows the effectiveness of using temazepam to provide daytime sleep in preparation for night activity. It also shows that soldiers are willing to take sleeping tablets to aid their sleep. The next phase of investigation is to test whether performance and alertness are improved, after a period of sleep deprivation, by temazepam induced rest prior to its onset.

In the meanwhile this study provides conclusive evidence that $20 \mathrm{mg}$ of temazepam improves the lengt畐 and quality of enforced daytime rest compared t placebo.

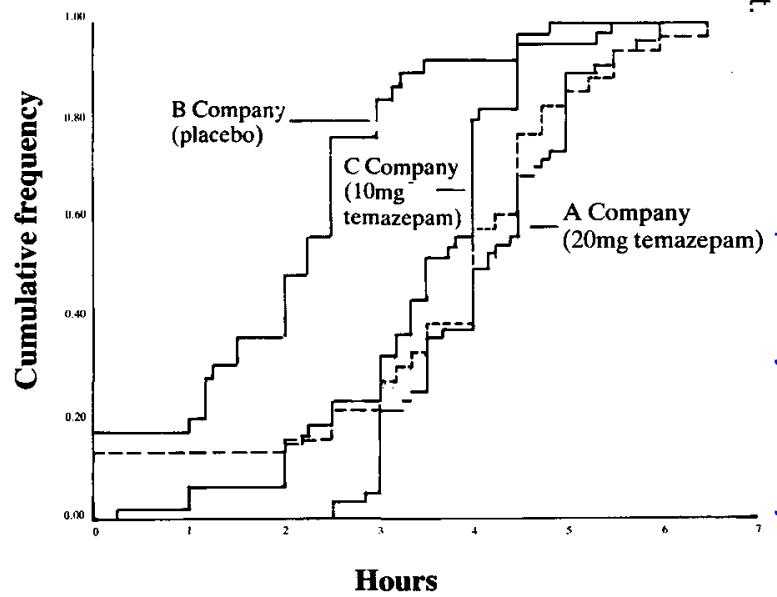

Fig 1. Cumulative distributions of sleep length by treatment group. The group who did not take a tablet is shown by the broken line. 

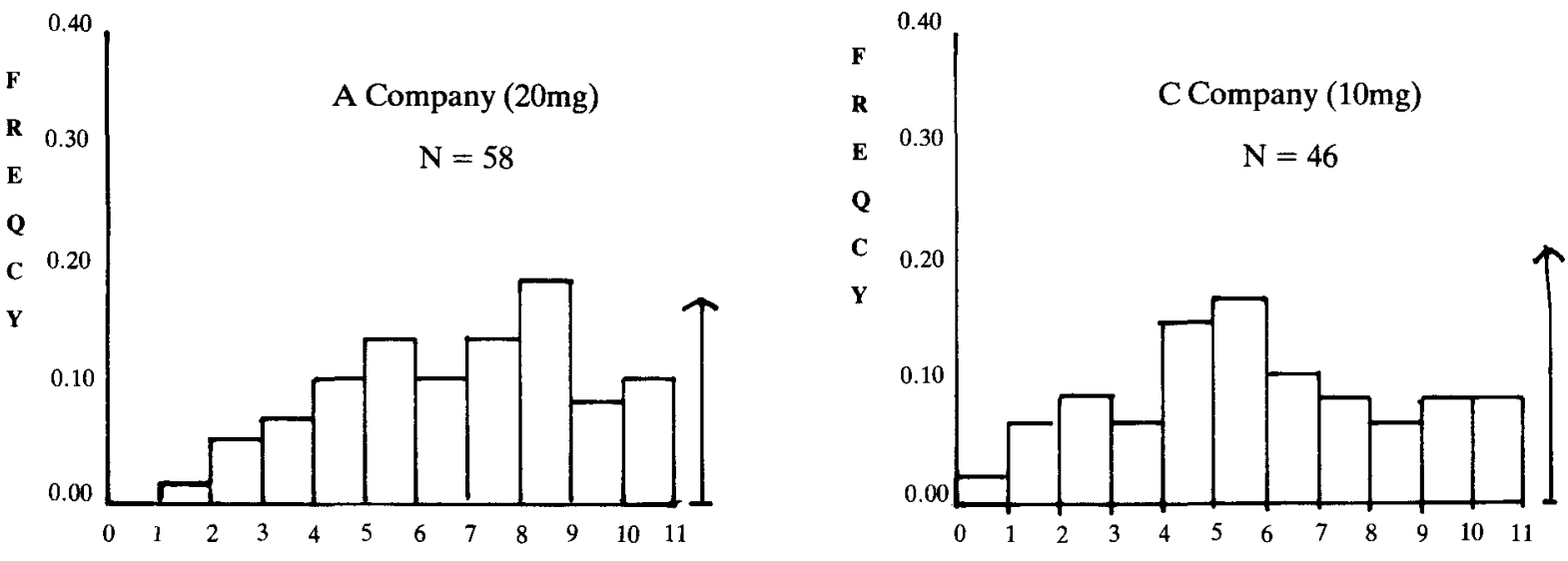

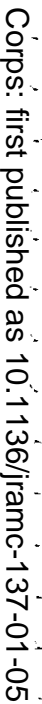
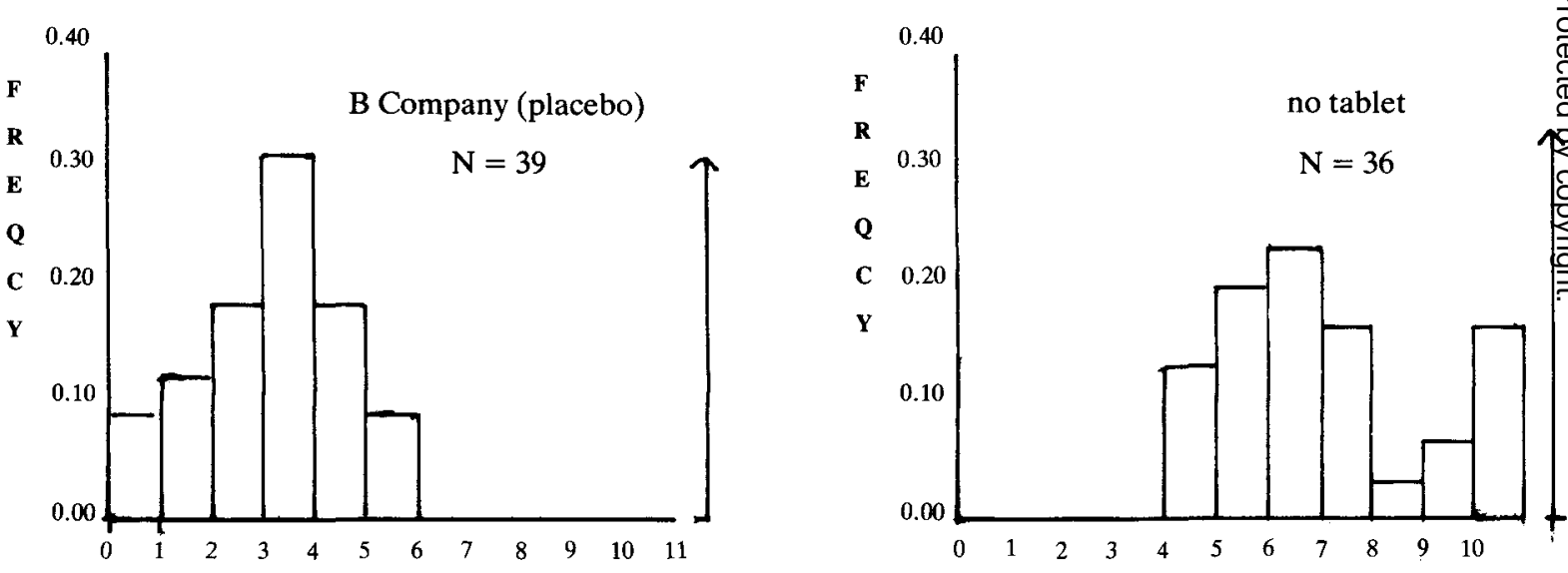

Fig 2. Distributions of Subjective Sleep Quality. 

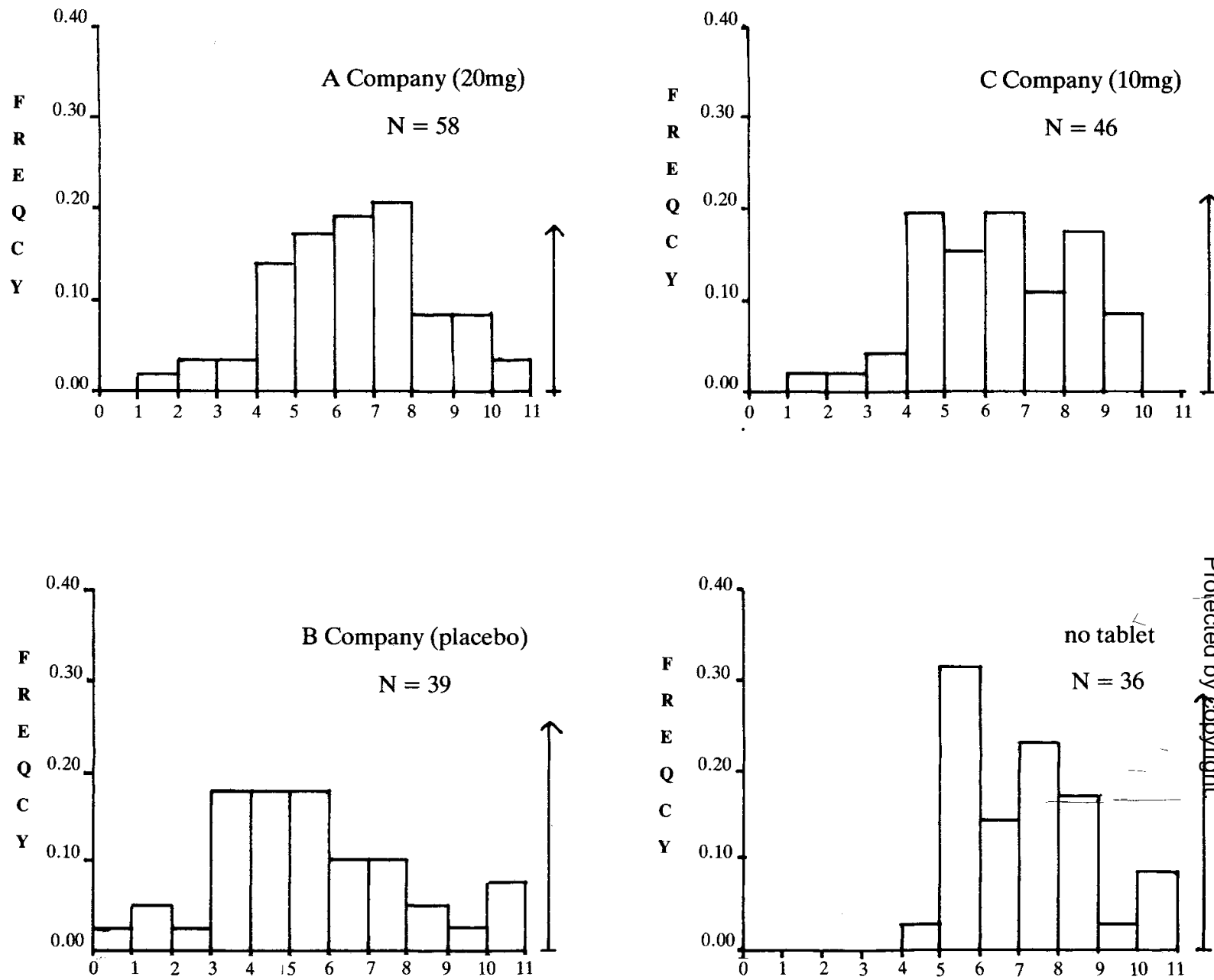

Fig 3. Distributions of subjective alertness.

Notes on Figs 2 and 3.

The vertical scale on each histogram refers to frequency. This enables the scale for all histograms to be the same. The number contributing to each bar is the frequency value corresponding to the height of the bar multiplied by the value of $N$ printed in the top righthand corner of each histogram. The vertical arrow at the right of each histogram indicates the height that equates to ten individuals. 


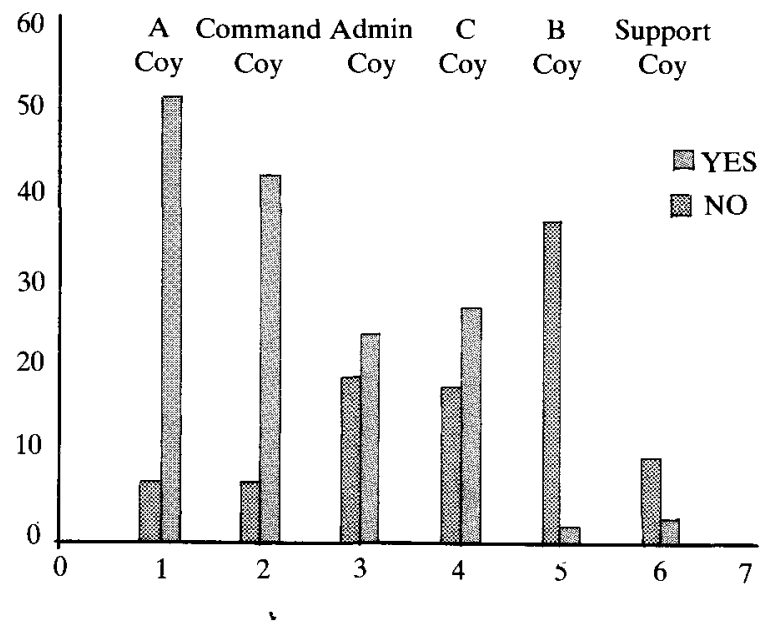

Fig 4. Numbers claiming that the tablet helped.

\section{Acknowledgements}

My thanks to Group Captain A N Nicholson, RAF and $\mathrm{Mr}$ M Spencer from the RAF Institute of Aviation Medicine for their advice and statistical assistance. My thanks also to Lieutenant Colonel R W Trigger PARA, MBE for permission to conduct this trial within his battalion.

\section{REFERENCES}

1 1. Nicholson A N, Pascoe P A, Roehrs T, et al. Sustained performance with short evening and morning sleeps. Aviat Space Enviro Med 1985; 56: 105-114.

2. Haslam D. Sleep loss and and sleep management. Army Training News April 1990.

3. Harry T V A, Latham A N. Hypnotic and residual effects of temazepam in volunteers. Br J Clin Pharmacol 1980; 9: 618-620.

4. WESNES K, WARBURTON D M. Effects of temazepam on sleep quality and subsequent mental efficiency under normal sleeping conditions and following delayed sleep onset. Neurobiology 1986; 15(3-4): 187-191.

5. Salonen M, Aantaa E, Aaltonen L, Hovi-Viander M, KanTO J. A comparison of the soft gelatin capsule and the tablet form of temazepam. Acta Pharmacol Toxicol 1986; 58(1): 49-54.

6. Borbley A A, Mattmann P, Loeffe M. Hypnotic action and residual effects of a single bedtime dose temazepam. Arzneim Forsch 1984; 34(1): 101-103.

7. IRJala J, Kanto J, Salonen M. Temazepam or midazolam for night sedation - a double blind study. Anaesthesia $1989 ; \mathbf{4 4 ( 8 )}$ : $685-687$.

8. Briggs R S, Castledean C M, KRAFt C A. Improved hypnotic treatment using chlormethiazole and temazepam. Br Med J 1980; 280(6214): 601-604.

9. Roth T, Piccione P, Salis P, Kramer M, KafFeman Mo Effects of temazepam, flurazepam, quinalbarbitone 0 . 7 sleep; psychomotor and cognitive function. $\mathrm{Br} J \mathrm{Cl}$. Pharmacol 1979; 8(1): 475-545.

10. FUCCELla L M. Bioavailability of temazepam in so gelatin capsules. Br J Clin Pharmacol 1979; 8: 25S-31S. 